\title{
Tool Life and Surface Integrity Characteristics of SLM and C\&W Inconel 718 in Dry and MQL Condition
}

\author{
Sasidharan Periane ( $\nabla$ sasinc87@gmail.com ) \\ University of Tours https://orcid.org/0000-0002-9005-2212 \\ Arnaud Duchosal \\ University of Tours \\ Sébastien Vaudreuil \\ Euromed University of Fes \\ Hicham Chibane \\ INSA Strasbourg \\ Antoine Morandeau \\ Advanced Assisted Manufacturing Solutions (AAMS) \\ Michael Anthony Xavior \\ School of Mechanical Engineering \\ Jonathan Cormier \\ Institut Pprime \\ René Leroy \\ University of Tours
}

\section{Research Article}

Keywords: Selective Laser Melting, Tool life, MQL, Aeronautic Heat Treatment, Tool wear

Posted Date: January 17th, 2022

DOI: https://doi.org/10.21203/rs.3.rs-1247744/v1

License: (1) (1) This work is licensed under a Creative Commons Attribution 4.0 International License. Read Full License 


\section{Abstract}

In this paper, a tool life test was performed using PVD coated insert on Inconel 718 (IN718) samples. The tool life was tested on IN718 workpiece fabricated through conventional (Cast \& Wrought) and additive (Selective Laser Melting) process routes. The as-built SLM samples were subjected to two heat treatments such as Hot Isostatic Pressing (HIP) and Aeronautic Heat Treatment (AHT). This study aimed to evaluate the machining behavior of C\&W and SLM IN718 from the machining point of view such as tool wear, chip appearance, surface roughness, and residual stresses. The tool life tests were performed under a dry and near dry environment like using Minimum Quantity Lubrication (MQL). Meanwhile, the tool wear propagation under different cutting conditions is also explored. Under both the cutting conditions flank wear and fracture of the cutting edge are the most predominant failure modes minimizing the tool life. The microhardness, surface roughness, and residual stress measurements were analyzed. The result indicates that the microstructural difference between the C\&W and SLM has more influence on the tool life compared to the machining environment. On machining, the SLM sample has $80 \%$ and $43 \%$ more tool life than the C\&W in dry and MQL machining. Comparing the dry and MQL machining of SLM, on using MQL the tool life is $30 \%$ less compared to the dry machining.

\section{Introduction}

Additive manufacturing techniques have transformed the nature of manufacturing these complex contoured components layer by layer from a 3D model [1-5]. Additive manufacturing has evolved as an economically viable alternative to conventional manufacturing as it does not require any special tool or fixture [6]. Selective Laser Melting (SLM) is one among the Laser powder bed fusion (L-PBF) manufacturing processes [7]. Generally, in the Laser powder bed fusion (L-PBF) technique, optimization of various process parameters such as laser power, laser scan speed, hatch spacing, etc. is essential to realize denser parts [8-11]. The as-built parts are less dense due to porosity which are introduced from existing pores of the powder, lack of fusion and entrapment of gas. The as-built samples are inferior in mechanical properties due to defects and due to the heterogeneous microstructure concerning C\&W parts [12]. Post - processing techniques like standard heat treatments like Hot isostatic processing and age hardening can be employed to minimize these defects inorder get the desired mechanical properties [13, 14]. Inconel 718 (IN718) is a precipitation strengthened nickel-based superalloy, has been developed extensively over the past four decades $[15,16]$. The remarkable weldability property of IN718 is due to low content Ti and Al which makes this material best suited for SLM [17-20]. IN718 is the preferred alloy for fabricating aerospace components such as turbines disks, compressors disks, blades, casing used at high-temperature applications [21].

IN718 parts maintain their mechanical properties up to $650^{\circ} \mathrm{C}$ due to the presence of strengthening phases [22]. As a consequence of its mechanical properties and low thermal conductivity, it is classified as a difficult material to machine $[23,24]$. While machining IN718, the low thermal conductivity and rapid work hardening rate result in elevated temperature leads to excessive tool wear [25]. During dry machining the temperature is more than $1000^{\circ} \mathrm{C}$, a strong tendency to welding to the cutting tool alters 
the tool geometry by Build Up Edge (BUE) formation. The abrasive wear occurs due to the presence of hard carbides such as $\mathrm{TiC}$ and $\mathrm{NbC}$ trapped at the tool-chip interface generates groove marks on the chip and starches on the tool [26].

The severe flank and notch wear are the dominant failure mode that occurs while machining IN718. The flank wear usually develops due to the adhesion of workpiece material on the tool surface [27]. In the milling of IN718, the intermitted thermomechanical load results in the notch wear and microchipping at the depth of cut. An increase in temperature at the cutting tool/workpiece interface directly relates to the increase in tool wear progression $[28,29]$. To increase the tool life, the type of coating deposited on the tool surface, its hot hardness property should be considered to minimize the plastic deformation at the cutting edge.

The use of cutting fluids has a major impact in increasing the tool life. Therefore, to enhance the tool life, cutting fluids-assisted machining is the only option to reduce the temperature at the cutting zone. Concerning environmental awareness Minimum Quantity Lubrication (MQL) was used as an alternative to conventional cutting fluids [30]. The use of lubrication minimizes the thermal softening [31], but the cutting tool is prone to plastic deformation which induces compressive residual stresses on the workpiece [32]. On subsequent machining during tool life, progressive deformation of the cutting edge influences the surface integrity (esp. surface roughness) to a greater extent [33].

The majority of machinability study discusses the machining influence on surface integrity and tool wear. According to the best of the authors' knowledge, no previous work has been reported on the influence of microstructure realized by two different process routes such as conventional (C\&W) and additive (SLM) on tool wear.

Therefore, the main objectives of this paper are:

- The Fabrication of samples and their post-processing methods like heat treatments.

- The mechanical characterization and microstructural analysis.

- Their influence on tool life and tool wear mechanisms.

- To identify different types of tool wear under dry and MQL machining.

- To study the micromorphology of chip pitch, chip segmentation frequency, and equivalent chip thickness in detail.

The methodology shows the influence of the microstructure and machining environment on the wear mechanisms. Finally, the conclusion summarizes the relevant results and the main parameters controlling tool life.

\section{Materials And Methods}

\subsection{Sample fabrication and post-processing}


Gas Atomized (GA) Inconel 718 alloy powder was used for the fabrication of samples. The chemical composition of the Inconel 718 powder in weight percentage of the elements is shown in Table 1.

Table 1

The IN718 composition in weight percentage (wt.\%).

\begin{tabular}{|llllllllllll|}
\hline Element & $\mathrm{Ni}$ & $\mathbf{A l}$ & $\mathrm{Co}$ & $\mathbf{C r}$ & $\mathrm{Cu}$ & $\mathrm{Ti}$ & $\mathrm{Mn}$ & $\mathrm{Mo}$ & $\mathbf{N b}+\mathrm{Ta}$ & $\mathrm{Al}$ & $\mathrm{Fe}$ \\
\hline wt. \% & 55.0 & 0.2 & 1.0 & 21.0 & 0.3 & 1.15 & 0.35 & 3.30 & 5.50 & 0.2 & Bal. \\
\hline
\end{tabular}

The samples were fabricated using an SLM $125 \mathrm{HL}$ machine, equipped with a Yb-fiber laser of 400W capacity. The powder particle size was found to be in the range of 40-90 $\mu \mathrm{m}$ measured using Horiba Camsizer X2. The SEM image of the powder particles is shown in Fig. 1 (a), the dendrites are visible on the magnified single powder particle in Fig. 1 (b). All the samples were CAD modeled to verify the sample position and the supports on the build platform using Magics software version 21. The process parameters used were laser power - $275 \mathrm{~W}$, scanning speed - $760 \mathrm{~mm} / \mathrm{s}$, the hatch distance - $120 \mu \mathrm{m}$, and the layer thickness - $50 \mu \mathrm{m}$ with a minimum scanning time of 12 seconds. The laser scan pattern used was of strips type, the angle between each strip was $67^{\circ}$. The build platform was preheated to $200^{\circ} \mathrm{C}$, the oxygen content $<0.03 \%$ was maintained. The vertical $\left(90^{\circ}\right)$ orientation sample shown in Fig. 1 (b) was fabricated in a controlled nitrogen gas atmosphere.

The samples were machined out from the build platform without any post-processing to study the microstructure and mechanical properties of the as-built samples. The heat treatment like Hot Isostatic Pressing (HIP) was performed at the target temperature of $1160^{\circ} \mathrm{C}$ and pressure of $102 \mathrm{MPa}$ was maintained for 3hrs. Subsequently, Aeronautic Heat Treatment (AHT) otherwise called as aging heat treatments was performed at $720^{\circ} \mathrm{C}$ for 8 hours, furnace cooled for 1.5 hours until the temperature reduces to $650^{\circ} \mathrm{C}$ and maintained for 8 hours followed by air-cooled as shown in TTT diagram of Fig. 2 . Even if this TTT diagram has originally been developed for a cast material and may not be suitable totally for SLMed Inconel 718 given the possible level of dendritic segregation, it already provides a good idea of the precipitation domains of $\gamma^{\prime}$ and $\gamma^{\prime \prime}$ strengthening phases and it is known to provide almost best static properties for an LPBF-processed Inconel 718 [34].

\subsection{Machining conditions}

The machining tests were performed on the 5 axis Hermle C40U CNC machine. An external generator (Lubrilean Digital Super- developed by SKF) was connected to the CNC machine to supply the oil mist. A computer equipped with Vogel software is connected to the generator to maintain a constant flow rate of $73 \mathrm{ml} / \mathrm{hr}$ at a pressure of 2 bar. The Vascomill MMS SE1, a Blaser oil based on synthetic esters, was used as the MQL oil. The samples were machined using a single insert with a tool diameter of $20 \mathrm{~mm}$ as in Fig. 3 (a) and the top view of the cutting process using a single insert is shown in Fig. 3 (b). A sample length of $60 \mathrm{~mm}$ was machined at a cutting speed $\left(V_{c}\right)$ of $30 \mathrm{~m} / \mathrm{min}$ for a feed rate $\left(\mathrm{f}_{\mathrm{z}}\right)$ of $0.1 \mathrm{~mm} /$ tooth. The axial depth of cut $\left(a_{p}\right)$ is $0.5 \mathrm{~mm}$ and the radial depth of cut $\left(a_{e}\right)$ is $9 \mathrm{~mm}$. The cutting conditions were 
followed from our previous studies, where the machinabilty study and surface integrity analysis were performed under different cutting conditions [36].

The tool used in this study is of reference R390-020A20-07M with the internal cooling channel for lubrication liquid, along with the insert mentioned in Table 2, which was recommended and provided by Sandvik Coromant.

Table 2

Insert details

\begin{tabular}{|ll|}
\hline \multicolumn{2}{|l|}{ Insert details: 390R-070204E-ML1040 } \\
\hline Lead angle & $90^{\circ}$ \\
\hline Coating & $\mathrm{PVD}(\mathrm{Ti}, \mathrm{Al}) \mathrm{N}$ \\
\hline Nose radius (reinforced edge) & $0.4 \mathrm{~mm} \pm 3 \mu \mathrm{m}$ \\
\hline Edge radius, $\mathrm{E}_{\mathrm{R}}$ & $27 \mu \mathrm{m} \pm 5 \mu \mathrm{m}$ \\
\hline
\end{tabular}

The cutting-edge radius $\left(E_{R}\right)$ of the inserts was measured using the GFM MikroCAD $\circledast$ equipment. At the same time the machined workpiece surface roughness, $\mathrm{Ra}(\mu \mathrm{m})$ was measured three times using 3D profilometer WYKO NT1100. The residual stress of the machined surface was measured using Bruker XRD D8 equipment. The parameters used for the residual stress measurement were $\mathrm{X}$-ray source $\mathrm{Mn}$, Angle 2 theta $153^{\circ}$, Miller indices 311 . Each test was repeated three times to obtain a range of standard deviation. The carbide insert was very small to fix the thermocouple to perform the temperature study.

\section{Results And Discussions}

\subsection{The influence of heat treatment on microstructure:}

Figure 4 (a) shows the microstructure of the coarse grain microstructure of Cast \& Wrought (C\&W) Inconel 718 alloy, the average grain size is $20 \mu \mathrm{m}$ which is obtained after hot forged and Aeronautic Heat Treated (AHT). The microstructure of the as-built samples contains columnar arc-shaped melt pool layers, the average grain size is $9.5 \mu \mathrm{m}$. The pores were highlighted in red circles (Fig. 4b) which are in the range of 30-60 $\mu \mathrm{m}$ diameter. The SEM image of the porosity (Fig. 4d) and the undiffuse powder particle after fabrication is shown in Fig. 4e. A homogenized microstructure with a average grain size of $8.9 \mu \mathrm{m}$ is evolved after HIP heat treatment by the complete dissolution of the melt pool boundaries and closure of the pores as in Fig. 4 (c). At $1100^{\circ} \mathrm{C}$ during the HIP heat treatment there is no $\delta$ precipitation since all the $\mathrm{Nb}$ is in solution state. On cooling the orthorhombic $\delta$ phase $\left(\mathrm{Ni}_{3} \mathrm{Nb}\right)$ is precipitated and distributed at the grain boundary along with the carbides shown in Fig. 4 (f). The precipitated needle-like $\delta$ phase at the grain boundary (Fig. $4 \mathrm{~g}$ ) restricts the grain growth [37] and reduces the ductility of the material [38]. 
Subsequently AHT heat treatment was perfomed where the strengthening phase $\mathrm{y}^{\prime}-\mathrm{Ni}_{3}(\mathrm{Al}, \mathrm{Ti})$ and $\mathrm{y}^{\prime \prime}-$ $\mathrm{Ni}_{3} \mathrm{Nb}$ precipitates using the remaining $\mathrm{Nb}$ available in the $y$ matrix. The average grain size after $\mathrm{AHT}$ heat treatment is $14.1 \mu \mathrm{m}$ which is $37 \%$ larger than grain size of the HIP sample.

\subsection{Evolution of tool wear}

According to the ISO 3688, the tool performance was evaluated by measuring the total time in cut (tc) in minutes until the average flank wear $(\mathrm{Vb})$ reaches $0.3 \mathrm{~mm}$. This section presents the results of the tool life test performed on additive SLM sample and conventional C\&W sample under dry and MQL machining environment. The PVD tool of $(\mathrm{Ti}, \mathrm{Al}) \mathrm{N}_{2}$ coating with reinforced edge, a lead angle of $90^{\circ}$ was used for all the machining conditions. The machining tests were interrupted after each time in cut $(t c)$ of 0.294 mins to estimate the tool wear.

Figure 5 shows the development of the tool wear (flank wear, $V b$ ) over time in cut $(t c)$ i.e the exact contact time of the insert with the workpiece. The tool wear curve was segmented into three phases: initial phase, linear phase, and catastrophic phase.

The tool wear pattern for dry machining of the C\&W sample started right from linear to the catastrophic phase. For the time in the cut of $t c 0$ to 0.588 mins the corresponding tool wear $V b$ was $0.33 \mathrm{~mm}$. While MQL assisted machining of the C\&W sample the initial tool wear $V b$ was only $0.07 \mathrm{~mm}$ for a tc of 0.294 mins. The linear phase was from tc of 0.294 to 0.588 mins the $V b$ was $0.09 \mathrm{~mm}$. The catastrophic phase duration was from $t c 0.588$ to 1.177 mins during which the tool wear $V b$ have exceeded the useful tool life of flank wear $(\mathrm{Vb})$ more than $0.3 \mathrm{~mm}$.

On machining SLM under the dry condition, the initial phase was from tc 0 to 0.588 mins during this phase the tool wear rapidly progressed to a $V b$ of $0.08 \mathrm{~mm}$. In the linear phase $t c$ from 0.588 to 1.471 mins, the wear was rather in uniform rate attaining a $V b$ of $0.103 \mathrm{~mm}$, and in the catastrophic phase $t c$ from 1.471 to 2.941 mins, the flank wears $V b$ was $0.3 \mathrm{~mm}$. On machining SLM using MQL the tool wear progressed to a $V b$ of $0.08 \mathrm{~mm}$ during the initial phase from tc 0 to $0.588 \mathrm{mins}$. In the linear phase $t c$ from 0.588 to 1.471 mins the wear was uniform until $V b$ of $0.17 \mathrm{~mm}$. The catastrophic phase was from $t c$ 1.471 to 2.059 mins at this phase the measured $V b$ was $0.35 \mathrm{~mm}$. The tool wear pattern on the machining SLM sample was justifiable regarding the C\&W.

\subsection{Effect on surface roughness}

The surface roughness, Ra $(\mu \mathrm{m})$ was measured on samples after each machining pass in both dry and MQL conditions shown in Fig. 6 . The surface roughness measured on the $\mathrm{C} \& \mathrm{~W}$ sample has an increasing pattern as the tool wear progresses. Whereas the surface roughness decreases with an increase in tool wear on machining SLM samples in both dry and MQL conditions. Especially under dry machining of the SLM sample the lowest surface roughness of $0.15 \mu \mathrm{m}$ was recorded. Whereas, the highest the roughness value of $0.36 \mu \mathrm{m}$ was recored while machining $\mathrm{C} \& \mathrm{~W}$ sample under dry condition. 


\subsection{Evolution of residual stress in the different machining environment}

The residual stresses measured at the middle of the sample were compressive in nature irrespective of the workpiece and machining environment. In dry machining conditions, there is $36 \%$ reduction in the compressive residual stress as the flank wear $(\mathrm{Vb})$ increases from $0.06 \mathrm{~mm}$ to $0.3 \mathrm{~mm}$ concerning the SLM sample. While MQL machining there is a $66 \%$ reduction in the compressive residual stress for the same flank wear period shown in Fig. 7.

The thermal load produced during machining has a direct impact on tool wear and the surface quality of the machined workpiece. During machining, the cutting heat is mainly taken away by the chips in dry conditions and by cutting fluids in MQL conditions. Apart from that large quantity of the thermal stress is transferred to the tool and only a small quantity is transferred into the workpiece and into the surroundings. The quantity of heat dissipates into the workpiece $(\mathrm{Qw})$ accumulates as residual stress [39].

More heat dissipates into the machined surface results in compressive residual stress during dry and MQL machining. Using MQL resulted in less thermal load (less heat dissipation to the machined surface) and high mechanical load, which maintained the compressive residual stress. The magnitude of the compressive residual stress decreases as the tool wear progresses. This trend is due to machining with a sharp tool tip results in maximum mechanical load and minimum thermal load. Whereas, as the tool wear progresses, the cutting edge becomes blunted which results in maximum thermal load and minimum mechanical load.

The residual stress value also remained more or less in equilibrium irrespective of the different microstructure possessed by the SLM sample compared to the C\&W sample.

\section{Discussion}

\subsection{Influence of heat treatment on mechanical properties}

The hardness of the samples was determined by the average of 25 measurements after applying $20 \mathrm{kgf}$ (or $200 \mathrm{~N}$ ) load for 15 seconds to each sample. The hardness value of the as-built, HIP and HIP-AHT samples about the cast and wrought IN718 is shown in Fig. 8.

The pattern of the hardness value is consistent with the work of Zong et al. [13]. In this work, they fabricated Inconel 718 using the Direct Metal Laser Sintering (DMLS) technique, where the hardness value increased following the aging heat treatment. The hardness value has increased linearly after each heat treatment; of about $30 \%$ after HIP. On subsequent AHT heat treatment, the hardness increased up to $42 \%$ concerning as-built hardness.

\subsection{Tool wear analysis under dry environment}


The tool wear progression was measured after every single pass, using the optical microscope (OM). The tool wear was investigated under Scanning electron microscope (SEM). Build Up Edge (BUE) formation (Fig. 9a) was observed on the insert at tc 0.588 mins while machining C\&W sample under dry condition. Excessive heat generated during dry machining, leads to micro-welding of the workpiece at the tool tip eventually leads to BUE formation. For the same tc of 0.588 mins on machining SLM sample under the dry condition the tool wear begins with the abrasion of the coating material in the form of severe grooves. In addition the diffusion of workpiece material on to the rake face and insert fracture at the cutting edge were observed as shown in Fig. 9 (b).

At tc of 1.1471 mins, the notch wear appears at the depth of cut (Fig. 10a) occurs due to machining of the deformed hardened surface resulting from the previous machining [32]. On futher machining, extensive abrasive wear along with adhesive wear resulted in flank wear (Fig. 10b) at the clearance face.

\subsection{Tool wear analysis under MQL environment}

The tool wear were analysed under MQL assisted machining of SLM and C\&W workpiece. The mechanical load is higher during the machining of C\&W which results in the fracture of the cutting edge. The wear mechanisms observed are adhesion of the workpiece material, coating delamination and diffusion of the chip material. Similar observation were made by Ibrahim et al [40] who also reported that, first the coating delamination occurs followed by the adhesion of workpiece material as in Fig. 11 (a). On further machining the sliding of the adhered material on the rake face resulted in abrasion wear and crack (Fig. 11b) which led to the tool failure at $t c 1.177$ mins reaching flank wear, $V b$ of $0.3 \mathrm{~mm}$. In spite of using MQL, the high carbides content in C\&W sample along with the sliding of adhered material (sandwiched between the chip and the coating) results in the abrasive wear on the rake face [41]. Fig. 11 (c) shows the rake face of the tool on machining SLM sample using MQL, as a consequence the coating delamination and adhered material zone is minimum. At $t c$ of 1.764 mins crack initiation at the rake face occurs along with the crater wear resulting in a flank wear, $V b$ of $0.17 \mathrm{~mm}$. On further machining the crack propagates leading to tool fracture as the load withstanding capacity of the tool is reduced at tc of 2.058 mins reaching the flank wear $V b$ of $0.3 \mathrm{~mm}$. The instability of the cutting tool on machining SLM under MQL condition results in chipping, crack and breakage (Fig. 11d) of the cutting edge leading to a poor tool life with reference to the machining of the SLM sample under dry condition.

Despite using MQL, the tool life is short concerning the dry machining of the SLM sample. The cuttingedge was unpredictable after a tc of 2.058 minutes. This could be due to the uneven thermal load over mechanical load leading to tool fracture.

\subsection{Chip morphology}

Cyclic or serrated types of chips were obtained on machining C\&W and SLM samples under dry as well as MQL conditions. This serrated chip formation is due to the occurrence of alternating high shear strain followed by low shear strain [42]. Observation on the shining side and serrations at the free surface of both the SLM and C\&W chip is quite interesting. The presence of intensive groove marks (Fig. 12a) at the shining side of the $\mathrm{C} \& \mathrm{~W}$ chips under dry conditions is due to the friction produced during the sliding of 
adhered material. Use of MQL have reduced the friction at the tool chip interface resulted in less intense groove marks (Fig. 12b) unlike dry machining of C\&W workpiece. The SLM chips under dry condition have a very smooth shining side, which shows that the machinability of SLM is good concerning C\&W. Certain black spots (Fig. 12c) were observed on the chips produced by dry machining of SLM sample, which could be due to the high temperature generated at the tool chip contact. Whereas, on machining under MQL the tool wear was not predictable which is evident from the undulation marks and adhesion of the coating present on the shining side of the chip (Fig. 12d). This could be due to the improper cut and thermal variation at the tool chip contact zone. The presence of groove marks on the shining side of the C\&W chips and the smooth shining side surface of the SLM chips show the machinability of SLM IN718 is better than C\&W IN718.

Figure 13 shows the schematic diagram that represents the characteristic features of the segmented chip. The maximum thickness of the segmented chip $\left(t_{1}\right)$, the maximum thickness of the segmented chip $\left(t_{2}\right)$, and pitch is the distance between two segmented peaks.

The serrated teeth formation occurs when the chip segmentation frequency is similar to the fluctuation frequency of the cutting force. The sheer instability results in a $50 \%$ increase in chip segmentation frequency while machining the SLM sample using MQL (Fig. 14a). Whereas, for the C\&W sample under dry and MQL condition and SLM sample under the dry condition the chip segmentation frequency is decreased to below $20 \mathrm{kHz}$. This is due to tool wear resulting in thermal softening and increased frictional forces.

Chip segmentation frequency [43] is calculated from equation 1

$$
f_{s}=\frac{V_{c} X f_{c} X \sin \emptyset}{p X t_{1}}
$$

In equation $1, f_{\mathrm{s}}$ is the chip segmentation frequency $(\mathrm{Hz}), V_{c}$ is the cutting speed $(\mathrm{m} / \mathrm{min}), f_{z}$ is the feed rate ( $\mathrm{mm} /$ tooth), $\phi$ is the cutting-edge angle (degrees), $p$ is the pitch of the serrated tool profile $(\mu \mathrm{m})$ and $t_{1}$ is the maximum chip thickness $(\mu \mathrm{m})$ as referred in Fig 13.

The formula for equivalent chip thickness ( $\left.t_{e}\right)$ was proposed by Wang et al [44].

$$
t_{e}=t_{2}+\frac{\left(t_{1}-t_{2}\right)}{2}
$$

In equation $2, t_{e}$ is the equivalent chip thickness $(\mu \mathrm{m}), t_{1}$ is the maximum chip thickness $(\mu \mathrm{m})$ and $t_{2}$ is the minimum chip thickness $(\mu \mathrm{m})$. While machining the $C \& W$ sample under dry conditions, the tool fails by BUE. The equivalent chip thickness $\left(t_{e}\right)$ is high due to increased frictional force which reduced the chip flow velocity (Fig. 14b) lead to microwelding of the workpiece material at the cutting edge. Frictional force gets considerably reduced on using MQL oil resulted in reduced equivalent chip thickness value due to increased chip flow velocity. 
Therefore, considering the surface integrity for the fatigue samples, the SLM HIP-AHT sample under dry machining is good a choice. To improve the tool life, some other metalworking fluids like flood cooling, cryogenic, or hybrid cryogenic - MQL assistance should be performed.

\section{Conclusions}

In this study, tool wear of PVD coated tool $(\mathrm{Ti}, \mathrm{Al}) \mathrm{N}$ was investigated using Cast and Wrought (as reference) and SLM processed samples. The SLM samples further had received two different heat treatments. The two-heat treatments were HIP and HIP-AHT leading to differences in hardness, the AHT providing greater hardness thanks to the precipitation of $y^{\prime \prime}+\gamma^{\prime}$ phases. To check the reliability of the tool, a tool lifetime test was conducted according to the ISO 3688 standard. The tool life test was performed under dry and MQL condition using a PVD-coated reinforced edged insert. The surface roughness and residual stresses of the samples were measured at different tool cut in time, tc and following conclusion were obtained:

- The additive SLM sample has $80 \%$ and $43 \%$ more tool life than the C\&W sample in both dry and MQL conditions.

- The tool life on machining SLM sample under MQL condition was $30 \%$ less compared to the dry machining.

- It is due to an increase in shear instability which is evident from the $50 \%$ increase in chip segmentation frequency resulted in chipping, crack and breakage of the cutting edge leading to a poor tool life.

- The decrease in the compressive residual stress as tool wear progresses irrespective of the cutting condition reveals the transition have taken place from maximum thermal load to minimum mechanical load.

\section{Abbreviations}

\begin{tabular}{|llll|}
\hline Nomenclature & & \\
$\mathrm{v}_{\mathrm{C}}$ & Cutting speed, m/min & $\mathrm{p}$ & Pitch, $\mu \mathrm{m}$ \\
$\mathrm{f}_{\mathrm{z}}$ & Feed rate, mm/tooth & $\mathrm{t}_{\mathrm{e}}$ & Equivalent chip thickness, $\mu \mathrm{m}$ \\
$\mathrm{a}_{\mathrm{p}}$ & Depth of cut, $\mathrm{mm}$ & $\mathrm{t}_{1}$ & Maximum chip thickness, $\mu \mathrm{m}$ \\
$\mathrm{a}_{\mathrm{e}}$ & Radial depth of cut, mm & $\mathrm{t}_{2}$ & Minimum chip thickness, $\mu \mathrm{m}$ \\
$\mathrm{v}_{\mathrm{b}}$ & Flank wear, $\mathrm{mm}$ & $\delta$ & Delta phase \\
$\mathrm{t}_{\mathrm{c}}$ & Cut in time, min & $\gamma^{\prime}$ & Gamma single prime \\
$\mathrm{f}_{\mathrm{s}}$ & Chip segmentation frequency $\left(\mathrm{H}_{\mathrm{z}}\right)$ & $\gamma^{\prime \prime}$ & Gamma double prime \\
$\varnothing$ & Cutting-edge angle, degrees & $\mathrm{Q}_{\mathrm{w}}$ & Dissipation of heat in the workpiece, Watts \\
\hline
\end{tabular}

\section{Declarations}


"The authors declare that submitted work is original and has not been published elsewhere in any form or language."

\section{a. Funding (information that explains whether and by whom the research was supported)}

"The authors declare that no funds or grants were received during the preparation of this manuscript."

\section{b. Conflicts of interest/Competing interests}

"The authors have no competing interests to declare that are relevant to the content of this."

\section{c. Availability of data and material}

All data generated or analyzed during this study are included in this published manuscript.

\section{d. Code availability}

Not applicable

\section{e. Ethics approval}

Not applicable

\section{f. Consent to participate}

Not applicable

\section{g. Consent for publication}

Not applicable

\section{h. Author's contribution}

Planning and sample fabrication were completed by SébastienVaudreuil, Hicham Chibane and Sasidharan Periane. The heat treatment and material characterisation were completed by Jonathan Cormier and Sasidharan Periane. The machining tests were completed by Sasidharan Periane, Arnaud Duchosal, Antoine Morandeau and Michael Anthony Xavior. The writing and original draft preparation, was done by Sasidharan Periane. The supervision and optimization of the article were completed by René Leroy, Arnaud Duchosal, Michael Anthony Xavior and Jonathan Cormier. All authors have given approval to the fnal version of the manuscript.

Acknowledgments

The authors thank, INSA Euromed, University of Fes, Morocco for the fabrication support and Cutting tool research and study center operators (CEROC, France) for machining support. Institut Pprime gratefully acknowledges "Contrat de Plan Etat - Région Nouvelle-Aquitaine (CPER)" as well as the "Fonds Européen de Développement Régional (FEDER)" for their support to the reported work.

\section{References}


1. Debroy T, Wei HL, Zuback JS, et al (2018) Progress in Materials Science Additive manufacturing of metallic components - Process, structure and properties. Prog Mater Sci 92:112-224. https://doi.org/10.1016/j.pmatsci.2017.10.001

2. Schmidt M, Merklein M, Bourell D, et al (2017) Laser based additive manufacturing in industry and academia. CIRP Ann 66:561-583. https://doi.org/10.1016/j.cirp.2017.05.011

3. European Powder Metallurgy Association EA (2012) Introduction to Additive Manufacturing Technology. 1-44

4. Zhang B, Li Y, Bai Q (2017) Defect formation mechanisms in selective laser melting: a review. Chin J Mech Eng 30:. https://doi.org/10.1007/s10033-017-0121-5

5. Tofail SAM, Koumoulos EP, Bandyopadhyay A, et al (2018) Additive manufacturing: scientific and technological challenges, market uptake and opportunities. Mater Today 21:22-37.

https://doi.org/10.1016/j.mattod.2017.07.001

6. Azam Fl, Majdi A, Rani A, et al (2018) An In-Depth Review on Direct Additive Manufacturing of Metals An In-Depth Review on Direct Additive Manufacturing of Metals. https://doi.org/10.1088/1757$899 X / 328 / 1 / 012005$

7. Keshavarzkermani A, Sadowski M, Ladani L (2018) Direct metal laser melting of Inconel 718: Process impact on grain formation and orientation. J Alloys Compd 736:297-305.

https://doi.org/10.1016/j.jallcom.2017.11.130

8. Hosseini E, Popovich VA (2019) A review of mechanical properties of additively manufactured Inconel 718. Addit Manuf 30:100877. https://doi.org/10.1016/j.addma.2019.100877

9. Cooke S, Ahmadi K, Willerth S, Herring R (2020) Metal additive manufacturing: Technology, metallurgy and modelling. J Manuf Process 57:978-1003. https://doi.org/10.1016/j.jmapro.2020.07.025

10. Moussaoui K, Rubio W, Mousseigne M, et al (2018) Effects of Selective Laser Melting additive manufacturing parameters of Inconel 718 on porosity, microstructure and mechanical properties. Mater Sci Eng A 735:182-190. https://doi.org/10.1016/j.msea.2018.08.037

11. Babu SS, Love L, Dehoff R, et al (2015) Additive manufacturing of materials: Opportunities and challenges. MRS Bull 40:1154-1161. https://doi.org/10.1557/mrs.2015.234

12. Chlebus E, Gruber K, Kuźnicka B, et al (2015) Effect of heat treatment on the microstructure and mechanical properties of Inconel 718 processed by selective laser melting. Mater Sci Eng A 639:647-655. https://doi.org/10.1016/j.msea.2015.05.035

13. Zhong C, Gasser A, Kittel J, et al (2016) Improvement of material performance of Inconel 718 formed by high deposition-rate laser metal deposition. Mater Des 98:128-134. 
14. Smith DH, Bicknell J, Jorgensen L, et al (2016) Microstructure and mechanical behavior of direct metal laser sintered Inconel alloy 718. Mater Charact 113:1-9.

https://doi.org/10.1016/j.matchar.2016.01.003

15. Peng H, Shi Y, Gong S, et al (2018) Microstructure, mechanical properties and cracking behaviour in a $Y^{\prime}$ ' - precipitation strengthened nickel-base superalloy fabricated by electron beam melting. Mater Des 159:155-169. https://doi.org/10.1016/j.matdes.2018.08.054

16. Ni M, Chen C, Wang X, et al (2017) Anisotropic tensile behavior of in situ precipitation strengthened Inconel 718 fabricated by additive manufacturing. Mater Sci Eng A 701:344-351. https://doi.org/10.1016/j.msea.2017.06.098

17. Yeh A, Lu K, Kuo C, et al (2011) Effect of serrated grain boundaries on the creep property of Inconel 718 superalloy. Mater Sci Eng A 530:525-529. https://doi.org/10.1016/j.msea.2011.10.014

18. Tucho WM, Cuvillier P, Sjolyst-Kverneland A, Hansen V (2017) Microstructure and hardness studies of Inconel 718 manufactured by selective laser melting before and after solution heat treatment. Mater Sci Eng A 689:220-232. https://doi.org/10.1016/j.msea.2017.02.062

19. Zhou N, Lv DC, Zhang HL, et al (2014) ScienceDirect Computer simulation of phase transformation and plastic deformation in IN718 superalloy: Microstructural evolution during precipitation. 65:270-286. https://doi.org/10.1016/j.actamat.2013.10.069

20. Lee S, Rasoolian B, Silva DF, et al (2021) Surface roughness parameter and modeling for fatigue behavior of additive manufactured parts: A non-destructive data-driven approach. Addit Manuf 46:102094. https://doi.org/10.1016/j.addma.2021.102094

21. Periane S, Duchosal A, Vaudreuil S, et al (2019) Machining influence on the fatigue resistance of Inconel 718 fabricated by Selective Laser Melting (SLM). Procedia Struct Integr 19:415-422. https://doi.org/10.1016/j.prostr.2019.12.045

22. Sharman A, Dewes RC, Aspinwall DK (2001) Tool life when high speed ball nose end milling Inconel $718^{\mathrm{TM}}$. J Mater Process Technol 118:29-35. https://doi.org/10.1016/S0924-0136(01)00855-X

23. Shokrani A, Dhokia V, Newman ST (2012) Environmentally conscious machining of difficult-tomachine materials with regard to cutting fluids. Int J Mach Tools Manuf 57:83-101. https://doi.org/10.1016/j.jimachtools.2012.02.002

24. Rinaldi S, Imbrogno S, Rotella G, et al (2019) Physics based modeling of machining Inconel 718 to predict surface integrity modification. Procedia CIRP 82:350-355.

https://doi.org/10.1016/j.procir.2019.04.150 
25. Zhu D, Zhang X, Ding H (2013) Tool wear characteristics in machining of nickel-based superalloys. Int J Mach Tools Manuf 64:60-77. https://doi.org/10.1016/j.ijmachtools.2012.08.001

26. Zhang RY, Qin HL, Bi ZN, et al (2020) Evolution of Lattice Spacing of Gamma Double Prime Precipitates During Aging of Polycrystalline Ni-Base Superalloys: An In Situ Investigation. Metall Mater Trans A Phys Metall Mater Sci 51:574-585. https://doi.org/10.1007/s11661-019-05536-y

27. Tool-life-and-cutting-forces-in-end-milling-Inconel-718-under-dry-and-minimum-quantity-coolinglubrication-cutting-conditions_2012_Journal-of-Cleaner-

28. Musfirah AH, Ghani JA, Haron CHCC, et al (2017) Tool wear and surface integrity of inconel 718 in dry and cryogenic coolant at high cutting speed. Wear 376-377:125-133.

https://doi.org/10.1016/j.wear.2017.01.031

29. Aramesh M, Montazeri S, Veldhuis SC (2018) A novel treatment for cutting tools for reducing the chipping and improving tool life during machining of Inconel 718. Wear 414-415:79-88.

https://doi.org/10.1016/j.wear.2018.08.002

30. Jeyapandiarajan P, Xavior MA (2017) Experimental Investigations on the Machinability of Inconel 718 Under Different Cutting Conditions. 38:295-304

31. Shokrani A, Dhokia V, Newman ST (2017) Hybrid Cooling and Lubricating Technology for CNC Milling of Inconel 718 Nickel Alloy. Procedia Manuf 11:625-632. https://doi.org/10.1016/j.promfg.2017.07.160

32. Oliveira ARF, da Silva LRR, Baldin V, et al (2021) Effect of tool wear on the surface integrity of Inconel 718 in face milling with cemented carbide tools. Wear 476:203752.

https://doi.org/10.1016/j.wear.2021.203752

33. Addona DMD, Raykar SJ, Narke MM, et al (2017) High Speed Machining of Inconel 718: Tool Wear and Surface Roughness Analysis. Procedia CIRP 62:269-274.

https://doi.org/10.1016/j.procir.2017.03.004

34. Xu J, Ma T, Peng RL, Hosseini S (2021) Effect of post-processes on the microstructure and mechanical properties of laser powder bed fused IN718 superalloy. Addit Manuf 48:102416. https://doi.org/10.1016/j.addma.2021.102416

35. Niang a (2010) Contribution à l'étude de la précipitation des phases intermétalliques dans l'alliage 718. Thèse

36. Periane S, Duchosal A, Vaudreuil S, et al (2020) Selection of machining condition on surface integrity of additive and conventional Inconel 718. Procedia CIRP 87:333-338.

https://doi.org/10.1016/j.procir.2020.02.092 
37. Kouraytem N, Varga J, Amin-ahmadi B, et al (2021) A recrystallization heat-treatment to reduce deformation anisotropy of additively manufactured Inconel 718. Mater Des 198:109228. https://doi.org/10.1016/j.matdes.2020.109228

38. Kuo YL, Horikawa S, Kakehi K (2017) Effects of build direction and heat treatment on creep properties of Ni-base superalloy built up by additive manufacturing. Scr Mater 129:74-78.

https://doi.org/10.1016/j.scriptamat.2016.10.035

39. Quan Y, He Z, Dou Y (2008) Cutting heat dissipation in high-speed machining of carbon steel based on the calorimetric method. Front Mech Eng China 3:175-179. https://doi.org/10.1007/s11465-0080022-5

40. Akhyar Ibrahim G, Che Haron CH, Abdul Ghani J, et al (2011) Performance of PVD-coated carbide tools when turning inconel 718 in dry machining. Adv Mech Eng 2011:

https://doi.org/10.1155/2011/790975

41. Ezugwu EO, Wang ZM, Machado AR (1998) The machinability of nickel-based alloys: A review. J Mater Process Technol 86:1-16. https://doi.org/10.1016/S0924-0136(98)00314-8

42. Priyadarshini A, Pal SK, Samantaray AK (2012) Finite element modeling of chip formation in orthogonal machining. Stat Comput Tech Manuf 9783642258:101-144. https://doi.org/10.1007/978-3642-25859-6_3

43. Rakesh M, Datta S (2020) Machining of Inconel 718 Using Coated WC Tool: Effects of Cutting Speed on Chip Morphology and Mechanisms of Tool Wear. Arab J Sci Eng 45:797-816.

https://doi.org/10.1007/s13369-019-04171-4

44. Wang C, Xie Y, Zheng L, et al (2014) Research on the Chip Formation Mechanism during the highspeed milling of hardened steel. Int J Mach Tools Manuf 79:31-48.

https://doi.org/10.1016/j.ijmachtools.2014.01.002

\section{Figures}

\section{Figure 1}

(a) IN718 GA powder with satellite particles and (b) vertically oriented samples 


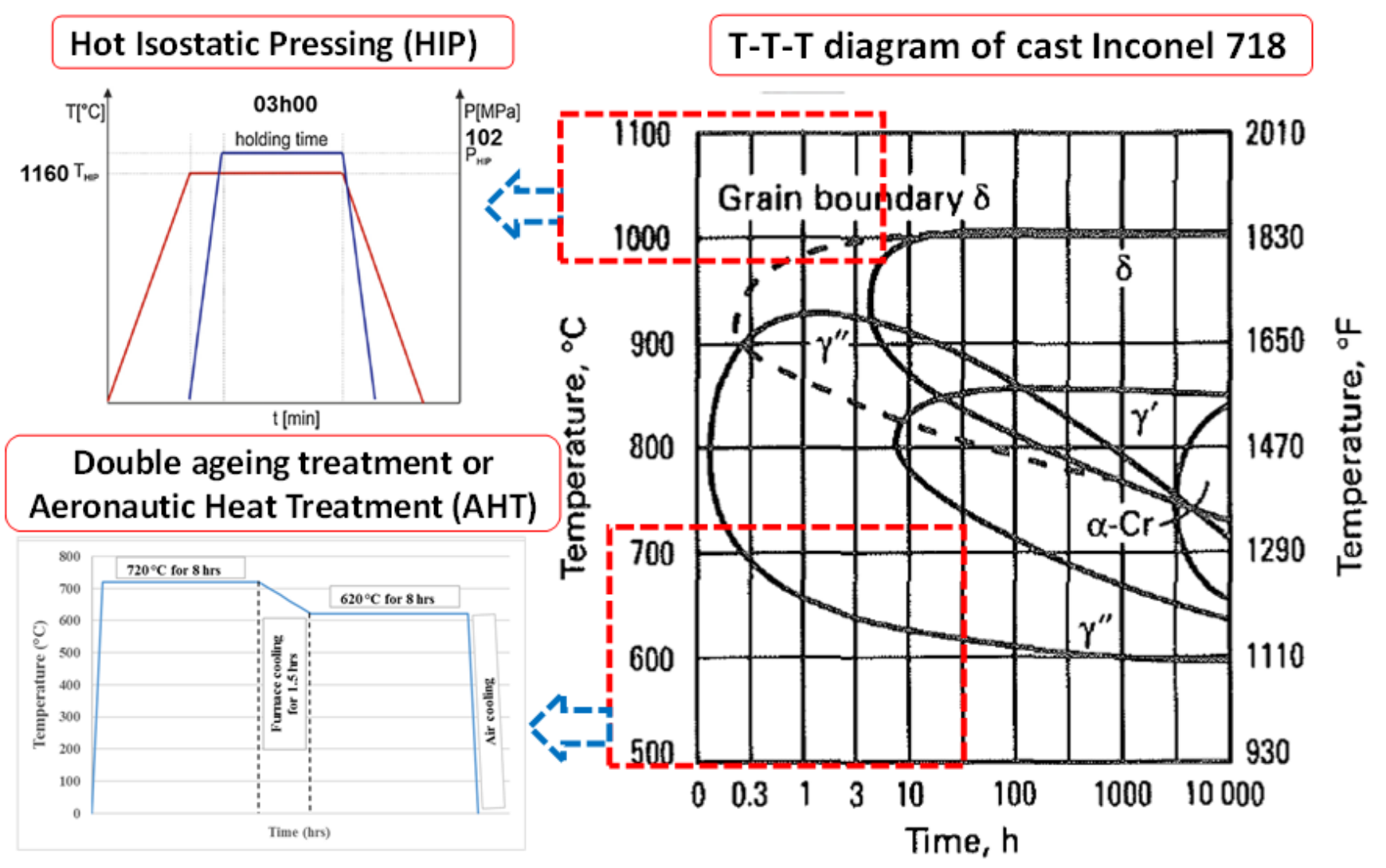

Figure 2

HIP and AHT heat treatment corresponding phase obtained using TTT diagram developed for C\&W Inconel 718
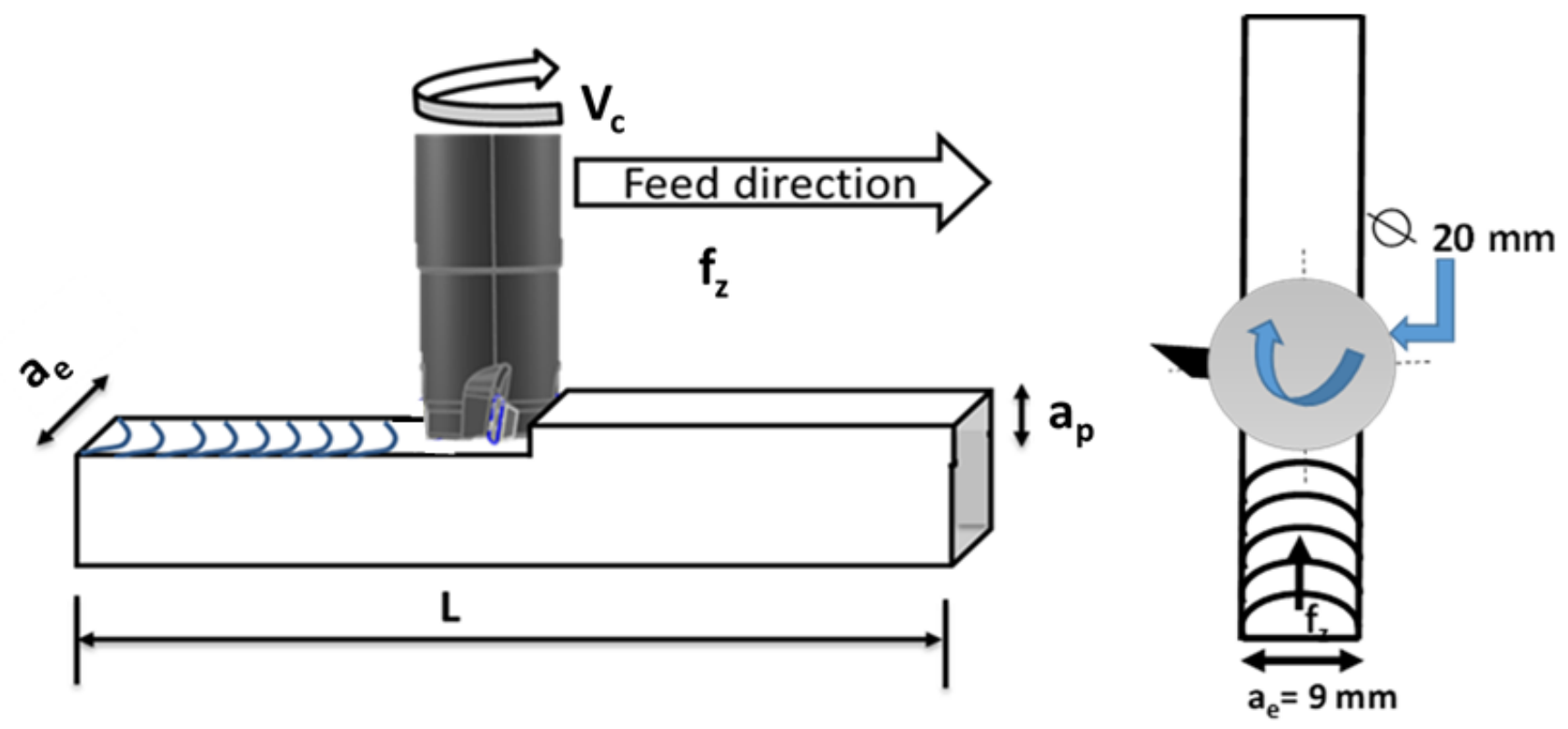

Figure 3 
(a) Schematic diagram of the machining and (b) Top-view of the metal cutting using a single insert.

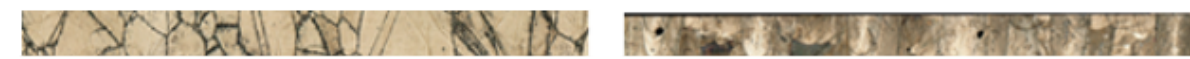

\section{Figure 4}

Microstructure of (a) C\&W (b) As-built and (c) SLM HIP+AHT, (d) porosity, (e) undiffused powder particles, (f) SLM HIP sample presence of $\delta$ phase and carbides, $(\mathrm{g}) \delta$ phase precipitation at the grain boundary.

\section{Figure 5}

Evolution of the flank wear $V b(\mathrm{~mm})$ under dry and MQL conditions on machining C\&W and SLM.

\section{Figure 6}

Evolution of the roughness $(\mu \mathrm{m})$ under dry and MQL conditions for SLM and C\&W.

\section{Figure 7}


Evolution of the residual stress under dry and MQL conditions on machining C\&W and SLM sample.

\section{Figure 8}

Hardness value for SLM as-built, SLM HIP, and SLM HIP+AHT compared to C\&W

\section{Figure 9}

(a) BUE formation on machining C\&W (b) Diffusion of workpiece material on machining SLM

Figure 10

(a) Notch wear (b) Flank wear on machining SLM workpiece.

\section{Figure 11}

(a) Material adhesion onto the rake surface (b) Crack initiation at the rake face (c) material adhesion onto the rake surface (d) Crater wear at rake surface and presence of thermal crack at cutting edge.

\section{Figure 12}

(a) Shinning side with grooving marks (b) Shinning side chip (c) Shining side of chip with tears (d) Shining side of chip with deformation.

\section{Figure 13}

Characteristics features of the segmented chip.

\section{Figure 14}


(a) Variation of chip segmentation frequency and (b) Variation of equivalent chip thickness of C\&W and SLM under dry and MQL machining. 